\title{
O INTERIOR E O EXTERIOR EM WITTGENSTEIN
}

\author{
Thaís Ap. Ferreira dos Santos ${ }^{1}$ \\ Universidade Estadual de Londrina
}

\section{RESUMO}

Este artigo pretende esclarecer mais especificamente os jogos de linguagem psicológicos em Wittgenstein. Para tanto, busca-se entender o conceito de linguagem wittgensteiniana e suas implicações para o jogo de linguagem psicológico. Wittgenstein entende que os estados internos são estabelecidos e aprendidos intersubjetivamente, rejeitando qualquer linguagem privada acerca do interior. Assim, compreende-se que a linguagem ordinária é extremamente complexa, pois é através da linguagem que expressamos nossos sentimentos e emoções, contudo cometemos equívocos sobre a aplicação dos jogos de linguagem por termos uma deficiência da visão panorâmica dos jogos de linguagem. Essa deficiência fez muitos filósofos anteriores a Wittgenstein, criarem ilusões acerca de interior e exterior, presentes em suas concepções antropológica ou da linguagem. A fim de poder entender tais problemas, o artigo se estrutura em uma breve introdução, argumentação sobre o interno e externo e conceptualização sobre exteriorização, descrição e a intersubjetividade que é recorrente na concepção antropológica de Ludwig Wittgenstein.

Palavras-chave: Wittgenstein, intersubjetividade, expressão, descrição.

\begin{abstract}
This paper intends to elucidate more specifically the psychological language games in Wittgenstein. Thereunto, it is attempted to understand Wittgenstein's language concept and its implications for the psychological language game. Wittgenstein understands that the intern states are established and learnt intersubjectively, and rejects any private language about the psychological interior. Thus, it is comprehended that the ordinary language is hugely complex, because it is through the language we express our feelings and emotions; nevertheless we commit mistakes in relation to the application of the language games, once we have a deficiency in their panoramic vision. This deficiency made many philosophers anterior to Wittgenstein create an illusion about interior and exterior, which is on their anthropological or language concepts. In order to be able to understand those problems, the paper is structured by a brief introduction, an argumentation about interior and exterior and a conceptualization about exteriorization, description and intersubjectivity, which is recurrent in Ludwig Wittgenstein's anthropological conception.
\end{abstract}

Keys-word: Wittgenstein, intersubjectivity, expression, description

\footnotetext{
${ }^{1}$ Graduanda em Filosofia na Universidade Estadual de Londrina (UEL) e bolsista de Iniciação Científica, email: thais.st@outlook.com; sob orientação da professora doutora Mirian Donat.
} 


\section{SEMINÁRIO DE PESQUISA EM CIÊNCIAS HUMANAS - SEPECH \\ Humanidades, Estado e desafios didático-científicos \\ Londrina, 27 a 29 de julho de 2016}

\section{INTRODUÇ̃̃O}

Ao longo da história da filosofia, certos filósofos favoreceram uma dualidade na nossa linguagem acerca do exterior e interior, até mesmos renomados autores da psicologia como Freud, reforçaram essa dicotomia, o que provocou em Wittgenstein a afirmação de que tudo isso não passa de uma "ilusão gramatical".

Essas concepções, tidas como metafísicas, geraram dois mundos: o do interno e o externo. O interno com características próprias como "algo" privado do sujeito e o externo se referindo a objetos do mundo físico. Conforme Fatturi: "podemos confundir nosso uso do conceito de mundo interior com a descrição de um mundo interior: Isto apontaria para a existência de um mundo paralelo ao mundo exterior" (2010, pág. 19). $\mathrm{O}$ que de fato ocorre para Wittgenstein é uma dificuldade gerada pela falta de um caráter panorâmico sobre os jogos de linguagem que gera "certas analogias entre as formas de expressão em diferentes domínios da nossa linguagem" (WITTGENSTEIN, 1991, § 90), sobretudo a descrição e a expressão, que são jogos que tem diferenças consideráveis, que caso contrário, não bem esclarecidas germinam em uma "escuridão gramatical".

Assim, Wittgenstein se propõe a fazer uma análise da linguagem, ou seja, uma investigação gramatical, que é uma tentativa de compreender como usamos os conceitos psicológicos.

A apresentação desse artigos estrutura-se em uma investigação conceitual sobre as proposições psicológicas de Wittgenstein, retirando a concepção metafísica presentes nos conceitos psicológicos e por fim abordaremos as formas expressivas e descritivas como uma elucidação dessas confusões.

\section{O INTERIOR}

Wittgenstein acredita que a nossa incompreensão com relação aos jogos de linguagem ocorre porque temos dificuldade de ter uma visão panorâmica dos jogos de linguagem. Como o próprio Wittgenstein assume esse "caráter panorâmico é de fundamental importância" ( $(122)$, visto que quem o tem sabe onde pode ser aplicado o jogo de linguagem, porque com esse "caráter" fazemos conexões, diferenciações, comparações que clarificam o uso dos múltiplos jogos de linguagem.

O austríaco não rejeita o conceito de interior, já que está fortemente enraizado em nossa cultura, fazendo parte de nossa forma de vida, o que ele pretende é eliminar toda a concepção metafísica envolta nesse conceito. Concepção essa presente na visão agostiniana $^{2}$ da linguagem (significado estabelecido pela relação nome-objeto), no qual toda palavra, se refere a "algo", na questão específica dos estados internos se dirige a "algo" do âmbito privado do sujeito, no caso de uma dor esse nome se referiria (definição ostensiva) a um estado interno que é a própria dor que o sujeito tem. A concepção metafísica também ocorre nos filósofos modernos, como Locke e Hume

\footnotetext{
${ }^{2}$ A visão agostiniana compreende os pensamentos de autores como Frege, Russel e o autor do Tractatus, os quais buscam uma essência para a linguagem, reduzindo a linguagem ao modelo nomeobjeto, sendo que o significado do nome é a referência desse.
} 


\section{SEMINÁRIO DE PESQUISA EM CIÊNCIAS HUMANAS - SEPECH \\ Humanidades, Estado e desafios didático-científicos \\ Londrina, 27 a 29 de julho de 2016}

(relação palavra-imagem mental) ${ }^{3}$, o que corresponderia a uma concepção mentalista da linguagem, em que a palavra se liga a uma imagem mental e, por meio dessa conexão, temos a significação dessa palavra; e o francês Descartes que caracteriza o homem com duas substâncias, espécies separadas entre si, uma chamada de res extensa, propriedade de extensão, a matéria, e a outra a res cogitans, propriedade do pensamento, o cogito, sendo que essas propriedades são independentes.

Desta concepção do homem decorre a ideia de que a consciência nos dá um acesso imediato e indubitável a tudo aquilo que se passa no nosso interior; do fato de que está sempre consciente do que ocorre em sua própria mente, decorre que o sujeito tem um conhecimento certo e seguro daquilo que ali se passa, daquilo tudo que pensa, por exemplo. (DONAT, 2009, pág.439).

Em Descartes, tudo o que percebemos do exterior, na verdade, são construtos de nossa mente, as sensações, emoções, percepções não são dos objetos em si, mas da criação do cogito, como uma peça teatral restritamente interna. Essas concepções metafísicas representam o que chamamos de linguagem privada, conforme Valle: "linguagem privada é aquela que carece de critérios públicos de significação" (2007, pág. 107).

A linguagem que trata do interior é vaga e imprecisa, o que não corresponde a algo oculto, de natureza misteriosa, mas de complexidades de uma linguagem ordinária, consoante Hebeche, "a eliminação da ocultação metafísica do interior faz-se junto da eliminação da metafísica do exterior, isto é, os conceitos de interior e exterior deixam de corresponder a processos mentais ou estados de coisas para serem compreendidos na linguagem" (2002, pág.84).

A concepção de linguagem wittgensteiniana é estabelecida intersubjetivamente. Conforme Pérez-Wicht: "la intuición central de Wittgenstein es que no entendemos mejor la naturaleza de lo mental mirando hacia adentro, como en la concepción cartesiana, sino observando las interaciones sociales" (2003, pág. 247). A linguagem ordinária não traça distinções metafísicas expostas acima entre interior e exterior, o que incita em erros de jogos de linguagem que os falantes podem cometer por não terem o conhecimento gramatical, porque não obtiveram um caráter panorâmico da multiplicidade dos jogos de linguagem.

O interior de Wittgenstein não é uma descrição de um estado interno, como fazemos com as descrições de locais que visitamos. $O$ interior aparece na expressividade dos estados internos, sendo que esses não são de natureza substancial, contudo estão inseridos em formas expressivas da linguagem. Mais adiante abordaremos com maiores detalhes as formas expressivas.

Nosso interior tem a possibilidade de ser revelado em nosso comportamento. Se vemos um sujeito a chorar, inferimos que seu estado interno é melancólico; ao olharmos para uma criança recém-nascida que grita e chora, percebemos que sente incômodo em seu organismo, porém o que caracteriza o interior não é somente o nosso comportamento, já que um robô pode facilmente representar comportamentos semelhantes aos nossos e ainda assim não consideramos que esse robô tenha um

\footnotetext{
${ }^{3}$ Ver com mais detalhes em 'Seguir regras' em Wittgenstein: uma leitura a partir da crítica ao mentalismo.
} 


\section{SEMINÁRIO DE PESQUISA EM CIÊNCIAS HUMANAS - SEPECH \\ Humanidades, Estado e desafios didático-científicos \\ Londrina, 27 a 29 de julho de 2016}

interior. Para olharmos esse robô com uma vida interior, necessitamos atribuir a ele qualidades inobserváveis, tais como vontade, desejo, dissimulação ${ }^{4}$. De acordo com Marques, “[...] não parece existir um conjunto necessário de comportamentos observáveis do qual se deduza infalivelmente um interior" ${ }^{\prime 5}$ (2003, pág. 14), visto que muitos dos estados internos podem ser ocultados. Wittgenstein não pesquisa sobre o interior com uma preocupação empírica, pois seu propósito é na manifestação do interno na linguagem.

Em contrapartida, os estados internos que queremos exteriorizar são identificados por meio da linguagem que devem estar de acordo com os critérios corretos de atribuição. Esses critérios são elaborados em uma comunidade, pois a linguagem é institucionalizada por estar em uma forma de vida, ou seja, dentro de um contexto, em uma determinada situação. É onde a palavra recebe seu significado. A forma de vida se refere ao linguístico e não-linguístico:

[...] de comportamento, assunções, práticas, tradições e propensões naturais que os humanos, como seres sociais, compartilham entre si, e que é, portanto, pressuposto na linguagem que usam; a linguagem está entrelaçada nesse padrão de atividade e caráter humano, e o significado é atribuído a suas expressões pela perspectiva compartilhada e pela natureza de seus usuários (GRAYLING, 1996, pág. 110).

Wittgenstein constata que para a exteriorização dos estados internos precisamos de critérios exteriores ${ }^{6}$, formados dentro da forma de vida, portanto, aprender exteriorizar é aprender dentro de um convívio a própria subjetividade e a sua manifestação, o que causa uma significação no uso que dessas manifestações fazemos.

\section{FORMAS EXPRESSIVAS E FORMAS DESCRITIVAS}

Voltando ao problema de objeto-designação, ou seja, a crítica a visão agostiniana, Wittgenstein; exemplifica que o conceito de dor é aprendido intersubjetivamente ${ }^{7}$ e que, portanto, não haveria uma sensação puramente interior, visto que o que está no "interior" é revelado, se mostra em nossa linguagem e comportamento.

Uma "exteriorização" é stricto sensu uma expressão psicológica na primeira pessoa do singular ( $Z, \S 472)$. É uma expressão do "eu" psicológico. Mas uma expressão na qual o "eu" é usado "como sujeito" e não "como objeto", como nas expressões que embora aparentem atribuir predicado ao "eu" atribuem-no ao corpo. Assim, proposições

\footnotetext{
${ }^{4} \mathrm{O}$ exemplo do robô é um experimento mental de António Marques.

${ }^{5}$ Itálico do autor.

${ }_{7}^{6} \int 580$, IF.

${ }^{7}$ \ 293 o argumento da caixa com besouro. Esse argumento se refere a dor, sob o modelo da linguagem privada de objeto-designação, no entanto, podemos compreender que qualquer estado interno também pode receber uma compreensão por estar no uso que fazemos da linguagem. No ato da fala, a palavra já recebeu uma institucionalização pelo ouvinte, sendo assim, ocorreu uma apropriação do significado que independe de qualquer objeto para se referir.
} 


\section{SEMINÁRIO DE PESQUISA EM CIÊNCIAS HUMANAS - SEPECH \\ Humanidades, Estado e desafios didático-científicos \\ Londrina, 27 a 29 de julho de 2016}

sobre meu próprio corpo não pertencem à gramática das exteriorizações (FAUSTINO, 1995, pág. 61).

Encontramos assim uma assimetria nas proposições psicológicas. Quando nos referimos a primeira pessoa do singular do presente do indicativo, estamos falando do nosso estado psicológico, cujo critério é: somente eu posso exteriorizar o que está contido no meu estado interno. Uma exteriorização é revelar o que sentimos que foi anteriormente me ensinado entre os sujeitos. Falar em primeira pessoa sobre o nosso "eu", é aprender que os estados internos são constituídos intersubjetivamente, no contexto social, histórico e cultural em que se vive. Certas expressões de estados internos carregam dentro de uma sociedade um valor moral, sendo positivo ou negativo sua exteriorização. Um exemplo seria a dor, em determinadas formas de vida, sua exteriorização pode significar um sinal de fraqueza, sendo vergonhoso manifestar essa sensação e, em outras formas de vida, o expressar a dor pode ser imoral. Uma forma de vida dita como nossas sensações e sentimentos devem ser exteriorizados.

É errôneo pensar que Wittgenstein toma para si a ideia objeto-designação, a solução para o problema é a exteriorização. Ao dizer "Eu estou com dor de cabeça" eu manifesto o que sinto dentro da forma de vida que estou inserida, retirando todo o ocultismo presente na ideia agostiniana. A forma de vida na qual fui introduzida ensinou-me que, para expressar a dor, preciso manifestar um conjunto de características que remetem a esse entendimento. Desse modo, aprendendo a linguagem revelo o que sinto. Conforme Donat:

A resposta de Wittgenstein é que o jogo de linguagem das sensações, cujas proposições não são descrições do que acontece em um suposto mundo interior, são exteriorizações da experiência. Por isso mesmo, não descrevem ou comunicam algo que eu sei, elas não tem valor cognitivo, pois com elas expressamos a nossa vontade, manifestamos nossos desejos e intenções, exteriorizamos aquilo que sentimos (2008, pág. 139).

As formas expressivas não têm valor cognitivo e sim as formas descritivas, isto é, são formas na terceira pessoa do singular do presente do indicativo que constituem a descrição do estado psicológico de outro sujeito. Por terem o caráter cognitivo, atribuem-se a essas proposições o valor de assertividade: "[...] aquilo que pode ser percebido e observado é que pode ser apresentado numa descrição, que poderá ser verdadeira ou falsa" (DONAT, 2008, pág. 136).

Wittgenstein nos mostra diversos tipos de descrições ${ }^{8}$, apresentando fatores que envolvem essas proposições: uma forma descritiva tem como base a percepção do observador sobre os fatos, podendo estabelecer os critérios de valor verdadeiro ou falso, lembrando que o observador também pode ser questionado, pois a percepção pode estar alterada ou mesmo o sujeito pode se confundir.

Quando o sujeito se confunde, este pode buscar informações com outros especialistas ou mesmo recursos tecnológicos para encontrar a iluminação de que precisa, o que não ocorre com as formas expressivas. Seria nonsense proferir "Não sei se tenho dor, talvez sinto algo". As formas descritivas se sustentam em evidências

\footnotetext{
${ }^{8} \mathbb{2} 24, \mathrm{IF}$.
} 


\section{SEMINÁRIO DE PESQUISA EM CIÊNCIAS HUMANAS - SEPECH \\ Humanidades, Estado e desafios didático-científicos \\ Londrina, 27 a 29 de julho de 2016}

empíricas, ao passo que não há sentido em afirmar que as formas expressivas sustentam-se nessas evidências.

Wittgenstein combate ao problema que essa confusão conceitual gera: um aspecto metafísico para as proposições psicológicas, "[...] es un gran error gramatical describir mis estados de consciencia sobre el modelo por el cual describo objetos físicos" (PAREJA, 1992, pág. 126). O austríaco explica o uso adequado das formas expressivas e descritivas, e consequentemente, conceitua a subjetividade.

\section{CONSIDERAÇÕES FINAIS}

O que nos constitui como seres humanos é essa característica da subjetividade de construirmos com os nossos semelhantes a nossa "essência", que é passível de revelação, por meio de uma linguagem que exterioriza nossos sentimentos, pois a significação do que queremos expressar se encontra no uso que fazemos das palavras, o que, consequentemente, se torna compreensível a qualquer ouvinte.

O interior, de acordo com Wittgenstein, é acessível aos demais sujeitos, não pertence ao privado, pois nós manifestamos o que antes era considerado interno e oculto para o público nas formas expressivas. Esse equívoco ocorreu na história da filosofia por ser confundido com as formas descritivas, que têm caracteres específicos para esse jogo de linguagem.

Com Ludwig Wittgenstein aprendemos que a subjetividade origina-se com o outro em uma forma de vida e nessas relações intersubjetivas que aprendemos a nos expressar, portanto, a significação se constitui no uso que é composto por regras públicas que tornam possíveis uma linguagem com sentido sobre o interior.

\section{REFERÊNCIAS BIBLIOGRÁFICAS}

BORTOLLO, Valle. A filosofia da psicologia em Ludwig Wittgenstein: sobre o "plano de tratamento dos conceitos psicológicos". Revista AdVerbum 2 (1) Jan a Jun de 2007: pp. 102-111.

DONAT, Mirian. Wittgenstein e as supostas posse privada e privacidade epistêmica da experiência. Rev. Filos., Aurora, Curitiba, v. 21, n. 29, p. 437-453, jul./dez. 2009.

Linguagem e significado nas Investigações Filosóficas de Wittgenstein: uma análise do argumento da linguagem privada. 2008. Tese (Doutorado) - São Carlos. Universidade Federal de São Carlos, 2008.

FATURRI, Arturo. Mundo interior e expressão: a filosofia da psicologia de Ludwig Wittgenstein. 2010. Tese (Doutorado) - São Carlos. Universidade Federal de São Carlos, 2010.

FAUSTINO, Sílvia. Wittgenstein o eu e sua gramática. São Paulo: Editora Ática, 1995. 


\section{SEMINÁRIO DE PESQUISA EM CIÊNCIAS HUMANAS - SEPECH \\ Humanidades, Estado e desafios didático-científicos \\ Londrina, 27 a 29 de julho de 2016}

GRAYLING, A. C. Wittgenstein. Trad. Milton Camargo Mota. São Paulo: Edições Loyola, 2002.

MARQUES, António. O interior linguagem e mente em Wittgenstein. Braga: Fundação Calouste Gulbenkian, 2003.

PAREJA, J. L. Gil de. La filosofía de la psicología de Ludwig Wittgenstein. Barcelona: PPU, S.A., 1992.

PEREIRA, Alessandro. 'Seguir regras' em Wittgenstein: uma leitura a partir da crítica ao mentalismo. Marília: Unesp, Vol. 6, nº 1, 2013.

PÉREZ-WICHT, Pablo Quintanilla. El linguaje de la intimidad. Sobre la constitución intersubjetiva de las emociones. In: FLÓREZ, Alfonso; HOLGUÍN, Magdalena; MELÉNDEZ, Raúl. Del espejo a las herramientas Ensayos sobre el pensamiento de Wittgenstein. Bogotá: Siglo del Hombre Editores, 2003. p. $241-260$.

WITTGENSTEIN, Ludwig. Investigações filosóficas. Trad. José Carlos Bruni. $5^{\mathrm{a}}$ ed. São Paulo: Nova Cultural, 1991. Coleção Os pensadores. 